J. Lake Sci. (湖泊科学), 2020, 32(1): 70-78

DOI 10. 18307/2020. 0107

(c) 2020 by Journal of Lake Sciences

\title{
太湖流域池塘养殖污染排放估算及其空间分布特征
}

\author{
彭凌云 ${ }^{1,2}$, 遆超普 ${ }^{2 * *}$, 李恒鹏 ${ }^{3}$, 王良杰 ${ }^{1}$, 颜晓元 ${ }^{2}$ \\ (1: 南京林业大学林学院, 江苏省南方现代林业协同创新中心, 南京 210037) \\ (2: 中国科学院南京土壤研究所, 土壤与农业可持续发展国家重点实验室,南京 210008) \\ (3: 中国科学院南京地理与湖泊研究所,湖泊与环境国家重点实验室,南京 210008)
}

摘 要: 池塘养殖是农业源污染的重要来源之一, 尤其在水网密布、渔业发达的太湖流域, 控制池塘养殖过程中氮、磷、化 学需氧量等污染物的排放,对于减轻水体富营养化程度、恢复水质健康、维持地区社会经济可持续发展具有重要意义. 基 于野外采样、人户调查、遥感解译等多种手段,结合 GIS 软件技术, 对太湖流域池塘养殖污染物的排放进行了估算. 结果表 明, 2014- 2015 年太湖流域总氮、硝态氮、铵态氮、总磷、可溶性磷、 $\mathrm{COD}_{\mathrm{Cr}}$ 的年排放量分别为 $6.1 \times 10^{6} 、 1.1 \times 10^{6} 、 1.7 \times 10^{6}$ 、 $1.3 \times 10^{5} 、 1.1 \times 10^{5}$ 和 $8.0 \times 10^{7} \mathrm{~kg}$. 其中鱼类池塘养殖排放系数分别为 $69.5 、 12.4 、 20.1 、 1.6 、 1.3$ 和 $919.8 \mathrm{~kg} / \mathrm{hm}^{2}$; 虾类池塘排 放系数分别为 $3.0 、 0.5 、 0.9 、 0.07 、 0.06$ 和 $39.3 \mathrm{~kg} / \mathrm{hm}^{2}$; 蟹类池塘排放系数分别为 $6.4 、 1.2 、 1.9 、 0.2 、 0.1$ 和 $84.9 \mathrm{~kg} / \mathrm{hm}^{2}$. 太湖 流域池塘养殖各类污染物排放分布特征为位于太湖西北部、南部和东北部的大部分地区池塘养殖污染物排放较高, 位于 太湖东部和太湖西南部的池塘养殖污染物排放较低. 池塘养殖业发达、饲料肥料投人高、养殖密度大等是造成该流域池 塘养殖污染物排放较高的主要原因. 针对太湖流域池塘养殖减排治理, 建议推行合理的池塘污染治理管理政策与策略, 综合考虑饲料利用率与投放量、养殖面积、养殖密度、养殖生物生态混养, 以及一些科学养殖管理措施和净化养殖废水的 技术措施等.

关键词: 太湖流域;太湖;渔业;池塘养殖;污染物排放;减排措施

\section{Estimates and characteristics of pollutant discharge from pond cultures in the Taihu Ba- $\sin *$}

PENG Lingyun ${ }^{1,2}$, TI Chaopu ${ }^{2 * *}$, LI Hengpeng ${ }^{3}$, WANG Liangjie ${ }^{1} \&$ YAN Xiaoyuan $^{2}$

(1: Collaborative Innovation Center of Sustainable Forestry in Southern China of Jiangsu Province, College of Forestry, Nanjing Forestry University, Nanjing 210037, P.R.China)

(2: State Key Laboratory of Soil and Sustainable Agricultural, Institute of Soil Science, Chinese Academy of Sciences, Nanjing 210008, P.R.China)

(3: State Key Laboratory of Lake Science and Environment, Nanjing Institute of Geography and Limnology, Chinese Academy of Sciences, Nanjing 210008, P.R.China)

Abstract: Pond culture, as a major component of aquaculture, is one of the important sources of agricultural source pollution. Pollutions from pond culture has been a big threat in the Taihu Basin, where with dense water network and developed fisheries. Hence, to reduce the eutrophication of water bodies, and to restore water quality and health, it is important to control the discharges of nitrogen, phosphorus, chemical oxygen demand and other pollution sources during pond culture. Based on field sampling survey and remote sensing interpretation, this study combined with GIS software to estimate the pollution load of pond culture in the Taihu Basin. The results showed that discharges of total nitrogen ( $\mathrm{TN})$, nitrate nitrogen $\left(\mathrm{NO}_{3}^{-}-\mathrm{N}\right)$, ammonium nitrogen $\left(\mathrm{NH}_{4}^{+}-\mathrm{N}\right)$, total phosphorus ( TP), dissoluble phosphorus ( DP) and chemical oxygen demand ( $\left.\mathrm{COD}_{\mathrm{Cr}}\right)$ in the Taihu Basin during 2014-2015 were $6.1 \times 10^{6}, 1.1 \times 10^{6}, 1.7 \times 10^{6}, 1.3 \times 10^{5}, 1.1 \times 10^{5}$ and $8.0 \times 10^{7} \mathrm{~kg}$, respectively. The discharge factor of the

* 2019-05-28 收稿; 2019-08-16 收修改稿. 中国科学院重点部署项目 (KZZD-EW-10-04) 资助.

** 通信作者; E-mail: cpti@ issas.ac.cn. 
above pollutions for fish ponds were $69.5,12.4,20.1,1.6,1.3$ and $919.8 \mathrm{~kg} / \mathrm{ha}$, shrimp ponds were $3.0,0.5,0.9,0.07,0.06$ and $39.3 \mathrm{~kg} / \mathrm{ha}$ and crab ponds were $6.4,1.2,1.9,0.2,0.1$ and $84.9 \mathrm{~kg} / \mathrm{ha}$. All of the pollutions from fish pond culture were much higher than those of shrimp and crab pond culture. The distribution characteristics of various pollution sources in pond culture in this basin were similar. The pollution discharge in the northwest, south and northeast of the Lake Taihu was higher in most areas than those in the east and southwest of it. Factors such as the well-developed pond farming industry and high fertilizer input result in high pollution discharge from ponds in this basin. Therefore, we proposed some reduction measures to control pond culture pollution in this basin, these could also be referenced by other basins.

Keywords: Taihu Basin; Lake Taihu; fishery; pond culture; pollutant discharge; mitigation measures

近年来, 农业源污染逐渐成为影响区域水环境的重要因素. 水产养殖源污染作为农业源污染的重要来 源之一,得到了越来越多的学者关注和研究 ${ }^{[1-3]}$. 据我国农业部渔业局发布的《2018 年中国渔业统计年 鉴》 ${ }^{[4]}$ 显示, 2017 年我国水产养殖面积达 7449.03 千 $\mathrm{hm}^{2}$,其中池塘养殖面积 2527.78 千 $\mathrm{hm}^{2}$, 占淡水养殖面 积的 47.12\%. 据我国 2010 年《第一次全国污染源普查公报》 ${ }^{[5]}$ 显示, 水产养殖业 (包括重点流域) 总氮 ( TN) 排放量为 10.36 万 $\mathrm{t}, \mathrm{TP}$ 排放量为 1.97 万 $\mathrm{t}$, 化学需氧量为 68.50 万 $\mathrm{t}$, 分别占农业污染源排放量的 $3.83 \%$ 、 $6.92 \%$ 和 $5.17 \%$, 分别占全国排放总量的 $2.19 \% 、 4.65 \%$ 和 $2.26 \%$. 根据欧阳佚亭等 ${ }^{[6]}$ 的估算, 2014 年我国 28 个省、自治区、直辖市 24 种淡水池塘养殖鱼类 TN、总磷 ( TP ) 和化学需氧量 (COD) 污染排放分别为 61388 、 11273 和 $592288 \mathrm{t}$.

太湖流域是我国经济发展最具活力的地区之一, 但近年来, 尤其是 2007 年蓝藻暴发之后, 水体污染严 重影响了该地区社会经济的可持续发展. 2014 年太湖健康状况报告显示, 太湖营养指数处于中度富营养程 度, 蓝澡数量处于不健康状态, 相较于 2007 年, 水质虽有好转趋势, 由劣 $\mathrm{V}$ 类变为 $\mathrm{V}$ 类, 但还没有达到健康 状态 $^{[7]}$. 太湖地区以淡水水产养殖为主, 其中又以池塘养殖为主要养殖方式, 大量研究显示 ${ }^{[8-10]}$, 池塘养殖 存在许多问题, 养殖户往往采用高密度、高投人、高产出的养殖模式, 饲料或肥料的过剩极易造成氮磷等污 染物的超标排放,引起周围水体的富营养化和水质恶化.

目前池塘养殖污染主要的研究方法有野外监测采样、野外调研、收集统计资料、模型估算等 ${ }^{[11]}$. 前人研 究多集中于单一或多种养殖模式下池塘养殖的野外监测 ${ }^{[12-15]}$, 对于流域尺度的研究较少, 在池塘养殖多种 污染源排放的空间分布方面研究较为欠缺. 因此, 本研究选取 $\mathrm{TN}$ 、硝态氮 $\left(\mathrm{NO}_{3}^{-}-\mathrm{N}\right)$ 、铵态氮 $\left(\mathrm{NH}_{4}^{+}-\mathrm{N}\right) 、 \mathrm{TP}$ 、可 溶性磷 $(\mathrm{DP})$ 和重铬酸盐指数 $\left(\mathrm{COD}_{\mathrm{Cr}}\right) 6$ 个指标, 于 2014-2015 年间通过野外监测采样获取整个太湖流域池 塘养殖污染源排放系数, 利用人户调研获取池塘排、换水以及饲料投人情况等数据, 结合遥感解译、GIS 软件 和统计数据, 获得池塘养殖面积数据并分析太湖流域池塘养殖污染排放及其空间分布特征, 为最终提出太 湖流域的池塘养殖污染控制措施和途径, 为减缓水体富营养化、提出水污染治理途径和促进生态环境可持 续发展提供科学依据和理论基础.

\section{1 材料与方法}

\section{1 研究区概况}

太湖流域 (图 1) 位于长江三角洲南翼, 流域面积为 $36895 \mathrm{~km}^{2}$, 由沿江滨海平原区、中部平原区和西部 低山丘陵区构成, 湖区面积达 $2338 \mathrm{~km}^{2}$. 流域属亚热带季风气候, 四季分明, 降水丰富, 多年平均气温为 $14.9 \sim 16.2^{\circ} \mathrm{C}$, 多年平均降雨量为 $1177 \mathrm{~mm}$. 太湖流域水网密布, 主要水系包括苕溪、南河、洮滆、黄浦江、杭州 湾水系等, 是我国城市分布最密集、经济发展最有活力的地区之一, 由于淡水资源丰富, 水产养殖业发达, 由 于高密度、高强度等不合理养殖模式等造成的水体污染比较严重 ${ }^{[16-17]}$.

\section{2 样品采集与分析}

在太湖流域分别选择溧阳市埭头镇、宜兴市丁蜀镇、湖州市吴兴区、苏州市吴中区东山镇、常熟市辛庄 镇 5 个地点 18 个养殖池塘进行实地采样. 根据水产品养殖周期, 在每次换排水时进行采样, 水样采集和保 存的依据是《水和废水监测分析方法》 (第四版 ${ }^{[18]}$. 水样室内分析指标包括 $\mathrm{TN} 、 \mathrm{NH}_{4}^{+}-\mathrm{N} 、 \mathrm{NO}_{3}^{-}-\mathrm{N} 、 \mathrm{TP} 、 \mathrm{DP}$ 和 $\mathrm{COD}_{\mathrm{Cr}}$, 其中 $\mathrm{TN} 、 \mathrm{NH}_{4}^{+}-\mathrm{N} 、 \mathrm{NO}_{3}^{-}-\mathrm{N} 、 \mathrm{TP}$ 和 DP 浓度采用 Skalar $\mathrm{San}^{++}$System 连续流动分析仪(荷兰 Skalar 仪器公 司) 进行测定, 检出限分别为 $0.040 \mathrm{mg} / \mathrm{L} 、 0.046 \mathrm{mg} / \mathrm{L} 、 0.015 \mathrm{mg} / \mathrm{L}$ ( 以 $\mathrm{N}$ 计)、 $0.01 \mathrm{mg} / \mathrm{L}$ 和 $0.01 \mathrm{mg} / \mathrm{L}$ ( 以 $\mathrm{P}$ 
计); $\mathrm{COD}_{\mathrm{Cr}}$ 采用多用途微电脑 $\mathrm{COD}$ 快速测定仪( Levibond 公司) 测定.

\section{3 入户调研与统计数据}

在 2014-2015 年间共进行 3 次人户调研,选取太湖流域江苏省、浙江省和上海市的一批具有代表性的 池塘养殖户展开全面调查, 多次实地调查多家池塘养殖农户和企业, 与养殖户进行交流. 通过人户调研, 全 面了解和掌握了太湖流域池塘养殖的具体情况，主要包括养殖模式、养殖规格、养殖面积/体积、养殖周期、 苗种、投放量、水体交换情况, 换水频率、换水比例、换水总量、排水去向、饲料肥料名称、主要成分及施用量、 施用方法等. 并通过查阅太湖流域各个地区的统计资料,获取各区鱼、虾、蟹池塘养殖面积.

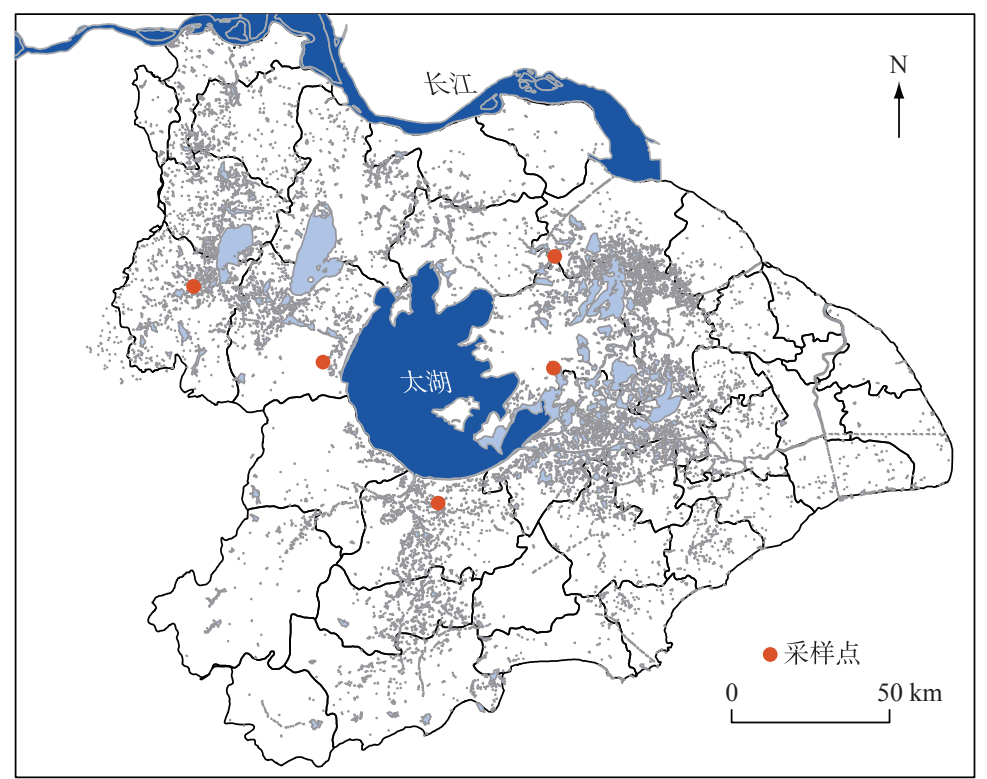

图 1 研究区、池塘湖库及采样点分布

Fig.1 Study area, ponds, lakes and sampling sites in the Taihu Basin

\section{4 遥感解译}

为获取太湖流域各地区池塘养殖的面积和详细空间分布数据, 本研究通过 eCognition 软件运用面向对 象的分析方法对 2014-2015 年太湖流域的遥感影像进行解译, 利用 ARC/INFO 进行拓扑检查, 然后自动统 计不同土地利用类型的面积,最后在 ArcMap10.3 中提取出池塘养殖的面积和空间分布. 影像资料来自资源 三号卫星, 分辨率为 $5.8 \mathrm{~m}$. 初步解译完成后, 利用野外实际采样 GPS 定位验证解译所得土地利用类型和池 塘养殖面积,其总精度达到 $90.21 \%$,符合遥感解译精度要求.

\section{5 污染排放计算}

根据人户调研, 太湖流域主要有鱼、虾、蟹 3 种养殖类型, 以常熟为例, 鱼、虾、蟹养殖面积占池塘养殖总 面积的 $98 \%$ 以上. 因此, 研究中分别在溧阳、宜兴、湖州、苏州、常熟地区设置了野外观测点, 对 3 种养殖种类 的池塘养殖污染物浓度进行测定, 并分别计算排放系数,最后利用各区统计资料 3 种池塘养殖面积计算整 个流域池塘养殖污染物排放量. 鉴于个别地区统计资料中各类养殖池塘面积的缺失, 我们采用 3 类池塘排 放的污染物平均值及遥感解译获取的池塘面积计算.

池塘养殖污染物排放系数计算公式如下:

$$
P_{k j}=\sum_{i} Q_{i} \cdot \Delta C_{i}
$$

式中, $P_{k j}$ 为池塘养殖第 $k$ 种养殖类型 (鱼、虾、蟹) 的第 $j$ 种污染物的排放系数, $\mathrm{kg} / \mathrm{hm}{ }^{2} ; Q_{i}$ 为第 $i$ 次换水时的 排水量, $\mathrm{m}^{3} ; \Delta C_{i}$ 为第 $i$ 次换水时进水污染物浓度与出水污染物浓度的差值, $\mathrm{mg} / \mathrm{L}$.

池塘养殖污染物排放量计算公式如下: 


$$
F_{j}=\sum_{j} P_{j} \cdot S_{j}
$$

式中, $F_{j}$ 为池塘养殖第 $j$ 种污染物的排放量, $\mathrm{kg} ; S_{j}$ 为池塘养殖的面积, $\mathrm{hm}^{2}$.

\section{2 结果与分析}

\section{1 池塘养殖污染物排放系数}

结合池塘排/换水数据, 2014-2015 年间太湖流域池塘养殖不同养殖类型的各类污染物排放系数如表 1 所示.

表 1 太湖流域池塘养殖各污染源排放系数 $\left(\mathrm{kg} / \mathrm{hm}^{2}\right)$

Tab.1 Discharge coefficients of pollutions in different ponds farming in the Taihu Basin

\begin{tabular}{ccccccc}
\hline 种类 & $\mathrm{TN}$ & $\mathrm{NO}_{3}^{-}-\mathrm{N}$ & $\mathrm{NH}_{4}^{+}-\mathrm{N}$ & $\mathrm{TP}$ & $\mathrm{DP}$ & $\mathrm{COD}_{\mathrm{Cr}}$ \\
\hline 鱼 & 69.5 & 12.4 & 20.1 & 1.6 & 1.3 & 919.8 \\
虾 & 3.0 & 0.5 & 0.9 & 0.07 & 0.06 & 39.3 \\
蟹 & 6.4 & 1.2 & 1.9 & 0.2 & 0.1 & 84.9 \\
\hline
\end{tabular}

\section{2 池塘养殖污染物排放量}

根据各类养殖池塘面积数据及其排放系数, 计算出 $2014-2015$ 年间池塘养殖 TN 排放量为 $6.1 \times 10^{6}$ $\mathrm{kg}$, 其中 $\mathrm{NO}_{3}^{-}-\mathrm{N}$ 排放量为 $1.1 \times 10^{6} \mathrm{~kg}, \mathrm{NH}_{4}^{+}-\mathrm{N}$ 排放量为 $1.7 \times 10^{6} \mathrm{~kg}$; $\mathrm{TP}$ 排放量为 $1.3 \times 10^{5} \mathrm{~kg}$, DP 排放量为 $1.1 \times 10^{5} \mathrm{~kg} ; \mathrm{COD}_{\mathrm{Cr}}$ 排放量为 $8.0 \times 10^{7} \mathrm{~kg}$.

\section{3 池塘养殖污染源排放空间分布特征}

太湖流域池塘养殖 $\mathrm{TN} 、 \mathrm{NO}_{3}^{-}-\mathrm{N} 、 \mathrm{NH}_{4}^{+}-\mathrm{N} 、 \mathrm{TP} 、 \mathrm{DP}$ 和 $\mathrm{COD}_{\mathrm{Cr}}$ 排放量的分布特征(图 2)大致相同, 位于太湖西 北部的宜兴市、溧阳市、金坛市、常州市市辖区及丹阳市, 太湖南部的湖州市市辖区、德清县、吴江市,太湖东 北部昆山市、常熟市、苏州市市辖区池塘养殖污染物排放较高; 位于太湖东部的嘉定区、宝山区、闵行区、浦 东新区和上海市市辖区, 太湖西南部的临安市池塘养殖污染物排放较低. 其中湖州市污染源排放量最大, $\mathrm{TN}$ 排放量为 $8.1 \times 10^{5} \mathrm{~kg}, \mathrm{NO}_{3}^{-}-\mathrm{N}$ 排放量为 $1.4 \times 10^{5} \mathrm{~kg}, \mathrm{NH}_{4}^{+}-\mathrm{N}$ 排放量为 $2.3 \times 10^{5} \mathrm{~kg}$, TP 排放量为 $1.7 \times 10^{4} \mathrm{~kg}$, DP 排放量为 $1.4 \times 10^{4} \mathrm{~kg}, \mathrm{COD}_{\mathrm{Cr}}$ 排放量为 $1.1 \times 10^{7} \mathrm{~kg}$. 太湖流域池塘养殖污染源排放量最低的是上海市市辖 区, 该地区池塘养殖面积为 $58.3 \mathrm{hm}^{2}$, $\mathrm{TN}$ 排放量为 $1.5 \times 10^{3} \mathrm{~kg}, \mathrm{NO}_{3}^{-}-\mathrm{N}$ 排放量为 $272.8 \mathrm{~kg}, \mathrm{NH}_{4}^{+}-\mathrm{N}$ 排放量为 $440.6 \mathrm{~kg}$, TP 排放量为 $32.2 \mathrm{~kg}$, DP 排放量为 $27.3 \mathrm{~kg}, \mathrm{COD}_{\mathrm{Cr}}$ 排放量为 $2.0 \times 10^{4} \mathrm{~kg}$.

\section{3 讨论}

\section{1 池塘养殖污染源排放系数和排放量}

本研究中太湖流域不同池塘养殖类型污染物排放系数由大到小排序是:鱼类>蟹类>虾类,鱼类池塘养 殖污染物排放系数远远大于虾蟹类. 与戴捷等 ${ }^{[19]}$ 、陈家长等 ${ }^{[20]}$ 、陈东兴 ${ }^{[21]}$ 等的研究对比发现, 本研究中 $\mathrm{TN} 、 \mathrm{TP}$ 的总体排放系数相对较小, 主要由于研究区内河蟹养殖与青虾养殖比例较高, 以常熟市为例, 该地区 青虾、河蟹养殖面积占常熟市池塘养殖面积的 $31.3 \%$, TN 排放系数为 $18.0 \mathrm{~kg} / \mathrm{hm}^{2}$, 而传统草鱼养殖排放系 数为 $73.4 \mathrm{~kg} / \mathrm{hm}^{2}$, 远远高于青虾河蟹养殖排放系数, 较高的河蟹养殖比例导致了该地区较低的污染排放系 数, 同时高月香等 ${ }^{[22]}$ 对江苏代表性水产养殖排污系数测算研究发现, 河蟹养殖的 TN 和 TP 排放系数分别为 26.09 和 $4.11 \mathrm{~kg} / \mathrm{hm}^{2}$, 远低于鱼类养殖的 TN 和 TP 排放系数 ( 52.02 和 $8.26 \mathrm{~kg} / \mathrm{hm}^{2}$ ), 这与本研究的结果相 似, 主要原因在于河蟹、青虾等养殖品种因其食用水生植物、鲜活饲料和动物尸体等, 投放富含氮、磷等饵料 的量较少,并且河蟹、青虾等养殖塘的表层排水方式降低了排水过程中对底泥的扰动, 降低了底泥中氮、磷 等污染物的流失. 陈昕等 ${ }^{[14]}$ 的研究指出, 池塘淡水鱼养殖的 $\mathrm{COD}_{\mathrm{Cr}}$ 排放系数高达 $199.10 \mathrm{~kg} / \mathrm{hm}^{2}$, 而饵料的 投放是水产养殖 $\mathrm{COD}_{\mathrm{Cr}}$ 的主要来源, 养殖水体封闭, 养殖方式密集, 换水次数较少, 都会导致池塘养殖 $\mathrm{COD}_{\mathrm{Cr}}$ 排放系数偏高.

太湖流域池塘养殖总面积为 $230000 \mathrm{hm}^{2}$, 占整个流域水产养殖总面积的 $93.3 \%$, 是太湖流域最主要的水 

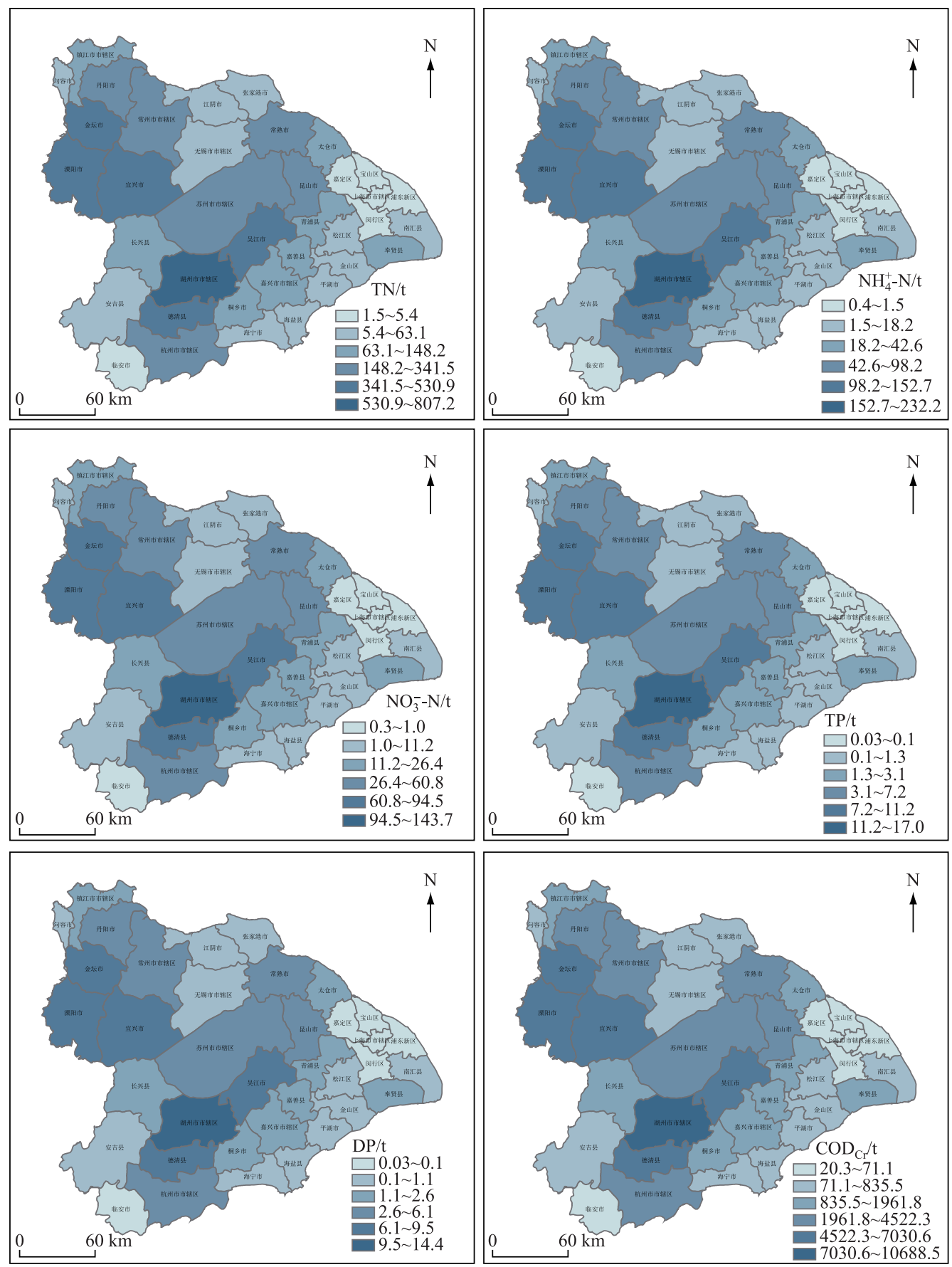

图 2 太湖流域池塘养殖污染物排放量的空间分布

Fig.2 Spatial distribution of pollutant discharge from pond farming in the Taihu Basin

产养殖方式 ${ }^{[23]}$. 本研究中太湖流域池塘养殖污染物排放量依次为 $\operatorname{COD}_{\mathrm{Cr}}\left(8.0 \times 10^{7} \mathrm{~kg}\right)>\mathrm{TN}\left(6.1 \times 10^{6} \mathrm{~kg}\right)>\mathrm{TP}$ $\left(1.3 \times 10^{5} \mathrm{~kg}\right)$. 与其他学者的研究成果 ${ }^{[12,21]}$ 对比发现, 本研究的结果偏小, 主要原因在于本研究中考虑的是 排换水, 水样只包括进水和排水, 测算出来的污染物浓度表征了水体中的可溶态和悬浮态污染物, 并不涉及 
沉积在池塘底泥中的污染物. 有研究显示, 池塘养殖过程中有 $14 \%$ 的氮 ${ }^{[24]}$ 和 $51 \%$ 的磷 ${ }^{[25]}$ 沉积到底泥中.

\section{2 池塘养殖污染源排放的空间分布特征}

池塘养殖污染物排放空间分布总体为位于太湖西北部的江苏省宜兴市、溧阳市、金坛市、常州市市辖区 及丹阳市, 太湖南部的浙江省湖州市市辖区、德清县、江苏省吴江市, 太湖东北部的江苏省昆山市、常熟市、 苏州市市辖区池塘养殖污染物排放较高,这些地区池塘养殖业发达, 是造成排放较高的主要原因.

区域养殖面积的差异是影响池塘养殖污染排放空间分布特征的重要因素之一. 本研究区内湖州市池塘 养殖最为发达, 池塘养殖面积居太湖流域各县市之首, 占太湖流域池塘养殖总面积的 $13.5 \%$, 这也直接造成 了湖州市市辖区污染的高排放. 另外, 通过实地调查走访, 发现湖州市主要池塘养殖种类为草鱼、鲈鱼等, 部 分混养青虾、河蟹等. 淡水池塘养殖草鱼需要投放大量的养殖饲料, 与河蟹、青虾等养殖鲜活饲料不同, 草鱼 养殖饲料不仅量大而且富含氮磷营养元素, 而频繁的换水排水将水体中多余的饲料排人受纳水体, 加重了 区域污染排放.

环太湖县市中, 无锡市辖区的污染排放最小, 主要由于早在 2008 年, 无锡市就开始实行池塘养殖循环 水技术, 避免了将养殖废水直接排人河流, 提高了养殖水体的循环利用效率和饲料利用效率. 中华线鳌蟹等 河蟹是东太湖区域的重要养殖种类, 在现行养殖方式中, 多流行多营养层次综合养殖方式 ${ }^{[26]}$, 水草成为了河 蟹养殖池塘的重要组成部分, 不仅降低了饲料的投放量, 更是可以吸收氨氮净化水质, 因此这也造成了东太 湖区域的池塘污染排放低于南太湖. 相比于环湖县市, 流域内未与湖区直接接壤的县市池塘养殖污染排放 大多低于环湖县市, 通过查阅资料发现, 一方面, 浙江省海宁等县市淡水池塘养殖以中华鳖和虾类养殖为主 导, 中华鳌与虾类养殖相对鱼类养殖产生的污染较小; 另一方面, 部分县市临海, 海水养殖是当地养殖的主 要方式, 淡水池塘养殖规模较小, 因此淡水池塘养殖所产生的污染排放也处于较低水准.

本研究部分地区 (镇江市辖区、丹阳、太仓等) 池塘养殖面积小, 未获得鱼、虾、蟹的养殖面积, 因此, 利用 遥感解译获得以上各地区池塘养殖面积, 这部分池塘养殖的污染物排放总量通过观测到的鱼虾蟹各类污染 物的排放系数平均值与遥感解译的面积获取. 尽管这部分池塘面积占近太湖流域池塘养殖总面积的 $6.7 \%$, 对污染物排放总量影响较小, 但通过以上方法获取的这些地区的池塘污染物排放量仍有一定的不确定性.

\section{3 池塘养殖污染源对太湖水体污染的贡献}

根据《地表水环境质量标准》(GB 3838-2002 $)^{[27]}$, 太湖流域池塘养殖各类污染物排放污染程度表现 为: $\mathrm{TN}$ 属于地表水劣 $\mathrm{V}$ 类、 $\mathrm{TP}$ 属于地表水 II 类、 $\mathrm{NH}_{4}^{+}-\mathrm{N}$ 属于地表水 III类、 $\mathrm{COD}$ 属于地表水 $\mathrm{I}$ 类. 因此,在这 6 个指标中, 尤其应该关注的是 $\mathrm{COD}_{\mathrm{Cr}} 、 \mathrm{TN}$ 和 $\mathrm{NH}_{4}^{+}-\mathrm{N}$ 的排放以及这些污染物对水体的影响. $\mathrm{TN}$ 和 $\mathrm{TP}$ 反映了 养殖动物对饲料、肥料的利用率, 经本研究调查, 该地区养殖户为获得高产量往往投人过多饲料和肥料, 未 利用的氮磷等的污染极易造成水体富营养化. $\mathrm{NH}_{4}^{+}-\mathrm{N}$ 和 $\mathrm{NO}_{3}^{-}-\mathrm{N}$ 是蛋白质矿化分解过程中的必有物质,硝化 反应受阻或者异养反应程度不够, 会造成 $\mathrm{NH}_{4}^{+}-\mathrm{N}$ 和 $\mathrm{NO}_{3}^{-}-\mathrm{N}$ 含量的增加. $\mathrm{DP}$ 占 $\mathrm{TP}$ 的 4/5, 说明有机磷含量较 少, 对水体污染影响较小, 但苏跃朋等 ${ }^{[28]}$ 的研究表明, 在池塘养殖系统中, 磷多沉积于池塘底泥, 因此, 对于 磷含量的估算可能偏低. $\mathrm{COD}_{\mathrm{Cr}}$ 反映了水体有机污染物的量, 值越高, 需要消耗的溶解氧越多, 极易造成水体 缺氧,水生生物难以生存,水体恶化 ${ }^{[29]}$.

2014 年太湖健康状况报告 ${ }^{[7]}$ 显示, $\mathrm{TN}$ 平均浓度为 $1.85 \mathrm{mg} / \mathrm{L}, \mathrm{TP}$ 为 $0.068 \mathrm{mg} / \mathrm{L}, \mathrm{NH}_{4}^{+}-\mathrm{N}$ 为 $0.16 \mathrm{mg} / \mathrm{L}$, 本研究太湖流域池塘养殖 $\mathrm{TN}$ 和 $\mathrm{NH}_{4}^{+} \mathrm{-N}$ (表 2) 排放平均浓度均高于太湖的平均浓度, 而 $\mathrm{TP}$ 排放浓度则低于 太湖. 2014 年太湖 $\mathrm{TN} 、 \mathrm{TP}$ 和 $\mathrm{NH}_{4}^{+}-\mathrm{N}$ 人湖总量分别为 $42000 、 2000$ 和 $12000 \mathrm{t}^{[7]}$, 其中太湖流域池塘养殖 $\mathrm{TN}$ 、 $\mathrm{TP}$ 和 $\mathrm{NH}_{4}^{+}-\mathrm{N}$ 的排放量分别占太湖污染物人湖总量的 $14.4 \% 、 7.4 \%$ 和 $14.6 \%$, 高于第一次全国污染源普查公 报中水产养殖排放占排放总量的比值, 已经成为太湖污染的重要来源之一.

表 2 太湖流域采样池塘污染物排放浓度

Tab.2 Concentrations of pollutions in the selected ponds in the Taihu Basin

\begin{tabular}{ccccccc}
\hline 污染物 & $\mathrm{TN}$ & $\mathrm{NO}_{3}^{-}-\mathrm{N}$ & $\mathrm{NH}_{4}^{+}-\mathrm{N}$ & $\mathrm{TP}$ & $\mathrm{DP}$ & $\mathrm{COD}_{\mathrm{Cr}}$ \\
\hline 平均浓度 $/(\mathrm{mg} / \mathrm{L})$ & 2.2 & 0.6 & 0.4 & 0.05 & 0.04 & 29.0 \\
\hline
\end{tabular}




\section{4 池塘减排措施}

太湖流域池塘养殖已成为太湖污染的重要来源之一, 其中 $\mathrm{TN} 、 \mathrm{TP} 、 \mathrm{NH}_{4}^{+}-\mathrm{N}$ 和 $\mathrm{COD}_{\mathrm{Cr}}$ 是影响太湖水质最主 要的污染物. 因此,制定合理的减排措施、使用合适的减排技术、推行池塘污染治理管理政策与策略等对治 理太湖流域池塘养殖污染具有重要意义. 针对池塘养殖污染物的形成原因, 可从污染物产生、排放及进人受 纳水体两方面进行生态防治. 一方面, 控制源头, 推行生态养殖模式, 在养殖过程中减少污染物排放. 本研究 中发现鱼类池塘养殖排放系数远远高于虾类和蟹类池塘养殖排放系数, 因此, 调整养殖搭配类型、选择适宜 的生态混养模式能很好地减少池塘养殖污染物排放, 如吴伟等 ${ }^{[30]}$ 研究了河蟹生态养殖对周围水环境的影 响, 发现生态养殖系统 (藻类一水草一螺一鱼一虾蟹等) 因各自生物学特性的相辅相成、相互制约, 能保证养殖 生物获得自身所需营养而生长, 又能保持水体自净, 达到安全标准. 杨芳等 ${ }^{[31]}$ 研究发现, $\mathrm{NH}_{4}^{+}-\mathrm{N}$ 的主要来源 是鱼类排泄, 所以需要对养殖密度加以控制, 还可采用三维植被网护坡技术或利用池塘养殖水灌溉稻田等 在排放前净化养殖池塘水质. 另外, 应该提高饲料的利用率, 即提高饲料工业的消化率和养殖植物的吸收 率, 并控制投喂量, 如刘崇新等 ${ }^{[32}$ 提出使用环保型水产饲料搭配合理投喂管理能够提高饲料在水中稳定性 和鱼虾消化吸收率, 从而减少污染物排放. 另一方面, 在换排水过程中, 可以通过不直接排放人周围水体, 在 途中设置农田、林地、草地、湿地等, 自然过滤养殖废水, 净化水质, 如陈金林等 ${ }^{[33]}$ 研究太湖地区非点源污染 控制时发现林带有利于截留和净化土壤径流中 $\mathrm{N} 、 \mathrm{P}$ 等物质, 杨林章等 ${ }^{\left[{ }^{[3]}\right.}$ 研究发现在水稻拔节期和灌浆期, 稻田人工湿地对低污染水中氮、磷有较高的净化作用. 其次, 可以通过合理布设复合生态滤床、人工浮岛、增 氧系统等新型生态材料与技术进行排污水的水质净化 ${ }^{[35-38]}$.

在管理层面, 浙江、上海和江苏在太湖流域开展了流域生态治理、流域水环境综合治理等来改善太湖水 环境现状, 但是针对池塘养殖的规范管理仍停留在各县市各自管理状态, 区域间发展存在不协调, 流域尺度 缺乏统一管理, 现有管理制度需进一步完善加强, 重视池塘养殖污染的危害, 推行合理的池塘污染治理管理 政策与策略, 建立池塘养殖环境影响评估体系. 同时大力发展复合生态养殖方式, 明确污染责任范围, 谁污 染, 谁治理. 加强池塘养殖污染防治宣传教育, 治理和宣传相结合. 另外在治理过程中加强区域间合作交流, 对重点污染区域进行针对性防控, 本研究太湖流域池塘养殖源污染重点控制区域是湖州市、德清县、宜兴市 等, 应加强重视.

\section{4 参考文献}

[ 1 ] Cao L, Wang W, Yang Y et al. Environmental impact of aquaculture and countermeasures to aquaculture pollution in China. Env Sci Pollut Res, 2007, 14(7): 452-462.

[ 2 ] Wang XH, Lu J, Zhang QZ et al. Spatial discharge characteristics and total load control of non-point source pollutants based on the catchment scale. Environmental Science, 2011, 32(9) : 2554-2561. [王夏晖, 陆军, 张庆忠等. 基于流域 尺度的农业非点源污染物空间排放特征与总量控制研究. 环境科学, 2011, 32(9) : 2554-2561.]

[ 3 ] Bryan WB, Jeremy LC. Commentary: Perspectives on aquaculture, urbanization and water quality. Comparative Biochemistry and Physiology, Part C, 2018, 217(2019): 1-4.

[ 4 ] Ministry of Agriculture Fisheries Bureau of China ed. 2017 National Fishery Economic Statistics Bulletin. China Agricultural Information Network, 2018. [农业部渔业局. 2017 年全国渔业经济统计公报. 中国农业信息网, 2018.]

[ 5 ] Ministry of Environmental Protection, National Bureau of Statistics, Ministry of Agriculture of the People's Reputation of China eds. The First National Pollution Census Bulletin, 2010. [中华人民共和国环境保护部、国家统计局、农业部. 第 一次全国污染源普查公报, 2010. ]

[6 ] Ouyang YT, Song GB, Chen JW et al. Grey water footprint and pollution loadings of freshwater pond-cultured fish in China. Environmental Pollution and Prevention, 2018, 40(3) : 317-328. [欧阳佚亭, 宋国宝, 陈景文等. 中国淡水池塘养 殖鱼类排污的灰水足迹及污染负荷研究. 环境污染与防治, 2018, 40(3) : 317-328.]

[ 7 ] Taihu Basin Authority of MWR, Water Resources Department of Jiangsu Province, Water Resources Department of Zhejiang Province et al. Taihu health report in 2014, 2015. [水利部太湖流域管理局, 江苏省水利厅, 浙江省水利厅等. 2014 年太湖健康报告, 2015.]

[8] Luo YX, Gao B, Yan XY et al. Estimating contribution of agricultural sources to aquatic nitrogen load in Taihu Lake re- 
gion: A case study of Yili River catchment. Journal of Agro-Environment Science, 2015, 34(12) : 2318-2326. [罗永霞, 高波, 颜晓元等. 太湖地区农业源对水体氮污染的贡献一以宜溧河流域为例. 农业环境科学学报, 2015, 34 (12) : 2318-2326.]

[ 9 ] Cai CF, Gu XH, Ye YT et al. Assessment of pollutant loads discharged from aquaculture ponds around Taihu Lake, China. Aquaculture Research, 2013, 44: 795-806.

[10] Dai XY. Studies on the water quality and nitrogen, phosphorus budget of seven types of aquaculture ponds in Suzhou region [Dissertation]. Suzhou: Soochow University, 2010. [戴修赢. 苏州地区七种养殖池塘水质及其氮、磷收支研究 [学位 论文]. 苏州: 苏州大学, 2010.]

[11] Gao B, Yan XY, Jiang XS et al. Research progress in estimation of agricultural sources pollution of the Lake Taihu region. J Lake Sci, 2014, 26(6) : 822-828. DOI: 10.18307/2014.0602. [高波, 颜晓元, 姜小三等. 太湖地区农业源污染核 算研究进展. 湖泊科学, $2014,26(6): 822-828$.]

[12] Huang H, Wang XQ, Wei XH et al. A research on the quantity of discharged of pollutant of freshwater breed aquatics in Hangjiahu area. Environmental Monitoring in China, 2007, 23(2): 94-97. [黄欢, 汪小泉, 韦肖杭等. 杭嘉湖地区淡 水水产养殖污染物排放总量的研究. 中国环境监测, 2007, 23(2): 94-97.]

[13] Ni M, Yuan JL, Chu TJ et al. Water quality and pollutant discharge of Litopenaeus vannamei pond in the reclamation region around Hangzhou Bay. Freshwater Fisheries, 2018, 48(2) : 107-112. [ 倪蒙, 原居林, 储忝江等. 环杭州湾围圼养 殖区凡纳滨对虾 (Litopenaeus vannamei) 池塘水质特征及污染物排放研究. 淡水渔业, 2018, 48(2): 107-112.]

[14] Chen X, Song Y, Wang WM et al. Study on the pollution of three different aquaculture modes in Gehu Lake area. J Anhui Agri Sci, 2013, 41(12): 5373-5377. [ 陈昕, 宋颖, 王伟民等. 滆湖地区 3 种不同鱼类养殖模式的污染强度对比研 究. 安徽农业科学, 2013, 41(12): 5373-5377.]

[15] Chen DX. Nitrogen and phosphorus budget in five types of aquaculture pond [Dissertation]. Shanghai: Shanghai Ocean University, 2012. [ 陈东兴. 5 种养殖池塘水质、污染物排放强度及氮、磷收支 [学位论文]. 上海: 上海海洋大 学, 2012.]

[16] Li J. The pressure evaluation of agricultural pollution in Taihu Lake Basin [Dissertation]. Jinan: Shandong Normal University, 2012.[李静. 太湖流域农业污染压力评估 [学位论文]. 济南: 山东师范大学, 2012.]

[17] Nanjing Institute of Geography \& Limnology, Chinese Academy of Sciences ed. Research and strategic thinking for water pollution control and ecological restoration in Taihu Basin. J Lake Sci, 2006, 18(3) : 193-198. DOI: 10.18307/2006. 0301. [中国科学院南京地理与湖泊研究所. 太湖流域水污染控制与生态修复的研究与战略思考. 湖泊科学, 2006, 18(3) : 193-198.]

[18] State Environmental Protection Administration ed. Methods for the monitoring and analysis of water and wastewater. 4th Edition. Beijing: China Environmental Science Press, 2002: 701-705. [ 国家环境保护总局. 水和废水监测分析方法: 第 四版. 北京: 中国环境科学出版社, 2002: 701-705.]

[19] Dai J, Li CL, Dend CZ et al. Investigation of nitrogen and phosphorus pollution and their pollution loads of pond crab farming in Honghu Valley. Environ Sci \& Technol, 2010, 33(5): 169-172. [戴捷, 李传岭, 邓楚洲等. 洪湖流域半封 闭池塘河蟹养殖氮磷污染负荷研究. 环境科学与技术, 2010, 33(5) : 169-172.]

[20] Chen JZ, Hu GD, Qu JH et al. TN and TP from pond crab farming in the Taihu Valley. Rural Eco-Environment, 2005, (1) : 21-23. [陈家长, 胡庚东, 崔建宏等.太湖流域池塘河蟹养殖向太湖排放氮磷的研究. 农村生态环境, 2005, (1) : 21-23.]

[21] Chen DX, Cai CF, Hua XM et al. The water quality and pollution intensity of aquaculture pond of fish, shrimp and crab during harvest draining. Freshwater Fisheries, 2015, 45(1): 30-34. [陈东兴, 蔡春芳, 华雪铭等. 鱼、虾、蟹养殖池塘 清塘排水水质及污染强度. 淡水渔业, 2015, 45(1): 30-34.]

[22] Gao YX, Zhang YM, Wang WM et al. Study on calculation of representative aquaculture pollution discharging coefficients in the Taihu Lake basin within Jiangsu Province. Journal of Agro-Environment Science, 2017, 36(7) : 1330-1336. [ 高月 香, 张毅敏, 王伟民等. 太湖流域江苏地区代表性水产养殖排污系数测算研究. 农业环境科学学报, 2017, 36 (7) : 1330-1336.]

[23] Luo YX. Nitrogen load of agricultural sources and spatial variations in the Taihu Lake Basin [Dissertation]. Nanjing: Nanjing Agricultural University, 2016. [罗永霞. 太湖流域农业源氮排放及其空间特征 [学位论文]. 南京: 南京农业大 学, 2016.] 
[24] Jackson C, Preston N, Thompson PJ et al. Nitrogen budget and effluent nitrogen components at an intensive shrimp farm. Aquaculture, 2003, 218: 397-411.

[25] Nhan DK, Verdegem MCJ, Milstein A et al. Water and nutrient budgets of ponds in integrated agriculture-aquaculture systems in the Mekong Delta Vietnam. Aquacult Res, 2008, 39: 1216-1228.

[26] Fang JG, Li ZJ, Jiang ZJ et al. Development strategy for ecological aquaculture and new mode of aquaculture farming. Engineering Sciences, 2016, 18(3): 22-28. [方建光, 李钟杰, 蒋增杰等. 水产生态养殖与新养殖模式发展战略研究. 中国工程科学, 2016, 18(3): 22-28.]

[27] National Standards of China GB 3838-2002. Environmental quality standards for surface water, 2002. [中华人民共和国 国家标准 GB 3838－2002. 地表水环境质量标准, 2002. ]

[28] Su YP, Ma S, Tian XL et al. An experimental study on nitrogen, phosphorus and carbon budgets in intensive pond of shrimp Fenneropenaeus chinensis. South China Fisheries Sci, 2009, 5(6): 54-58. [苏跃朋, 马甡, 田相利等. 中国对虾 精养池塘氮、磷和碳收支的研究. 南方水产, 2009, 5(6) : 54-58.]

[29] Zhu XD, Tu JZ, Cui SR et al. Study on the correlation of total organic carbon with chemical oxygen demand and biochemical oxygen demand in water. Transactions of the CSAE, 1999, (3) : 196-198. [朱杏冬, 涂金珠, 崔绍荣等. 养殖水中 总有机碳与化学需氧量和生化需氧量相关性的研究. 农业工程学报, 1999, (3) : 196-198.]

[30] Wu W, Fan LM, Qu JH et al. Effect of river crab eco-culture in ponds on water environment. Journal of Safety and Environment, 2006, 6(4) : 50-54. [ 吴伟, 范立民, 篗建宏等. 池塘河蟹生态养殖对水体环境的影响. 安全与环境学报, $2006,6(4): 50-54$. ]

[31] Yang F, Gao Y, Chen Q et al. Effects of freshwater polyculture fish ponds water quality on surrounding environment. Guangdong Agricultural Sciences, 2013, 4: 146-148. [杨芳, 高扬, 陈琴等. 淡水混养鱼塘水质对周围水环境的影响. 广东农业科学, 2013, 4: 146-148.]

[32] Liu CX, Cao ZX, Liu XM et al. Application situations and suggestions of pollutant abatement technology for aquaculture in China. Animals Breeding and Feed, 2018, (9): 119-124. [刘崇新, 操志翔, 刘新明等. 我国水产养殖污染物减排技 术应用现状及建议. 养殖与饲料, 2018, (9): 119-124.]

[33] Chen JL, Pan GX, Zhang AG et al. The controlling effects of shelter forest on non-point source pollution of agricultural lands in Taihu Lake area. Journal of Nanjing Forestry University, 2002, (6) : 17-20. [ 陈金林, 潘根兴, 张爱国等. 林带 对太湖地区农业非点源污染的控制. 南京林业大学学报: 自然科学版, 2002, (6) : 17-20.]

[34] Yang LZ, Shi WM, Xue LH et al. Reduce-Retain-Reuse-Restore technology for the controlling the agricultural non-point source pollution in countryside in China: General countermeasures and technologies. Journal of Agro-Environment Science, 2013, 32(1) : 1-8. [ 杨林章, 施卫明, 薛利红等. 农村面源污染治理的“4R” 理论与工程实践一一总体思路与 “4R” 治理技术. 农业环境科学学报, 2013, 32(1) : 1-8.]

[35] Liu JZ, Wang FW, Liu W et al. Nutrient removal by up-scaling a hybrid floating treatment bed (HFTB) using plant and periphyton: from laboratory tank to polluted river. Bioresource Technology, 2016, 207: 142-149.

[36] Song GX, Zheng JJ, Liu K et al. Research trend and focus on water remediation technology based on bibliometrics. Wetland Science, 2016, 14(2) : 185-193. [ 宋国香, 郑京晶, 刘康等. 基于文献计量学的水体修复技术研究趋势及热点 分析. 湿地科学, 2016, 14(2): 185-193.]

[37] Martin O, Sebastian S, Bruno E et al. Diurnal stratification of oxygen in shallow aquaculture ponds in central Europe and recommendations for optimal aeration. Aquaculture, 2019, 501. DOI: 10.1016/j.aquaculture.2018.12.005.

[38] Li YJ, Jin XC, Nian YG et al. Artificial floating island technology and its applied research. Technology of Water Treat$m e n t, 2007,(10): 49-51,77$. [李英杰, 金相灿, 年跃刚等. 人工浮岛技术及其应用. 水处理技术, 2007, (10): 49-51, 77. ] 